\title{
BMJ Open Perceived quality of nursing care and patient education: a cross-sectional study of hospitalised surgical patients in Finland
}

\author{
Weronica Gröndahl, ${ }^{1}$ Hanna Muurinen, ${ }^{2}$ Jouko Katajisto, ${ }^{3}$ Riitta Suhonen, ${ }^{2,4,5}$ \\ Helena Leino-Kilpi ${ }^{2,4}$
}

To cite: Gröndahl W, Muurinen $\mathrm{H}$, Katajisto $\mathrm{J}$, et al. Perceived quality of nursing care and patient education: a cross-sectional study of hospitalised surgical patients in Finland. BMJ Open 2019;9:e023108. doi:10.1136/ bmjopen-2018-023108

- Prepublication history for this paper is available online. To view these files, please visit the journal online (http://dx.doi. org/10.1136/bmjopen-2018023108).

Received 24 October 2018 Revised 11 February 2019 Accepted 12 February 2019

Check for updates

(c) Author(s) (or their employer(s)) 2019. Re-use permitted under CC BY-NC. No commercial re-use. See rights and permissions. Published by BMJ.

${ }^{1}$ Digestive and Urology Clinic, Turku University Hospital, Turku, Finland

${ }^{2}$ Department of Nursing Science, University of Turku, Turku,

Finland

${ }^{3}$ Department of Mathematics and Statistics, University of Turku, Turku, Finland

${ }^{4}$ Turku University Hospital, Turku, Finland

${ }^{5}$ City of Turku, Welfare Division, Turku, Finland

Correspondence to Hanna Muurinen;

haelmu@utu.fi,

hannamuurinen23@gmail.com

\section{ABSTRACT}

Objectives This study aims to analyse the relationship between patient education and the quality of surgical nursing care as perceived by patients. The background of the study lies in the importance of a patient-centred approach for both patient education and quality evaluation. Design This was a cross-sectional descriptive correlational study with surgical patients.

Setting Data were collected in 2013 in one hospital district in Finland.

Participants 480 hospitalised surgical patients.

Methods The data were collected using two structured instruments: one measuring the perceived quality of nursing care experienced by patients (Good Nursing Care Scale) and one measuring the received knowledge of hospital patients (RKhp). Data were analysed statistically using descriptive and inferential statistics to describe the sample and study variables. Pearson's correlation coefficients were used to analyse the association between the scales.

Results Surgical hospital patients evaluated the level of the quality of nursing care as high; this was especially true with reference to the environment and staff characteristics, but not to collaboration with family members. Most $(85 \%)$ of the patients had received sufficient knowledge preoperatively and they were familiar with the proceeding of their care and treatment after discharge; in particular, they had received bio-physiological knowledge, consisting of knowledge of the disease, symptoms and the physiological elements of care. The positive correlation between the perceived quality of surgical nursing care and received knowledge was strong, suggesting a positive relationship between patient education and improvement of the quality of nursing care.

Conclusions Based on the results, the quality of nursing care and patient education are interconnected. Thus, by improving patient education, the quality of nursing care can also be improved. It is particularly important to improve collaboration with family members and patients' own management strategies as well as the multidimensionality of educational knowledge.

\section{INTRODUCTION}

The evaluation of the quality of surgical patients' care is a fundamental responsibility
Strengths and limitations of this study:

- The design allows a patient-centred approach to the connection between the quality of patient care and patient education, as emphasised in recent healthcare strategies.

- The data were collected with valid and reliable instruments allowing comparison with earlier results and replication of the study in different clinical fields.

- The sample size is based on power analysis, but the response rate was difficult to define in the real-life context.

- The sample was collected within different surgical fields; generalisation of the results to a specific field would require new data.

- Patients' self-evaluation is one dimension in the evaluation of quality, and there is still a need to combine register data with these evaluations.

of professionals in surgical operative facilities. In this study, our special interest lies in the connection between the quality of nursing care and patient education as perceived by hospitalised surgical patients. Our theoretical assumption is that the higher the patients' perceptions of the knowledge received, the higher the perceived quality of surgical nursing care. Focus on patient education is thus key when it comes to improving the patient-centred quality of care. On the part of professionals, patient education requires a lot of time, competence to use different types of material, programmes and instruments, and skills to evaluate the empowerment of patients. ${ }^{12}$ It is therefore important to analyse the relationship between educational activities and the quality of care.

In earlier literature, the importance of in-patients' perceptions of quality of care and their experiences has been identified. ${ }^{3-6}$ Preoperative empowering information has been shown to improve the perceived perioperative quality of care, ${ }^{7}$ and educational activities 
are important for patient empowerment, ${ }^{8}$ as has been shown among older people. Furthermore, patient education is important for reducing preoperative anxiety, ${ }^{9}$ and it has a positive impact on professionals' performance. ${ }^{10}$ Patient-centredness and knowledgeable professionals with good communication skills seem to have an influential role in the experienced quality of nursing care, ${ }^{11}$ and there seems to be a connection between patient-centredness and health outcomes. ${ }^{12}$

In surgical care, many changes have influenced patient education in recent years, including an increase in ambulatory surgery, advances in anaesthesia and surgical techniques, new technological, educational alternatives, ${ }^{13} 14$ and shorter hospitalisation times. ${ }^{15}$ These changes indicate a need to support patients' self-empowerment to ensure the continuity of care and recovery at home. ${ }^{16}$ However, nurse-to-patient ratios in acute surgical units indicate a limited time for patient education, ${ }^{17} 18$ and the relationships between the quality of nursing care and different work-related factors are complicated. ${ }^{19}$ At the same time, the important role of patient safety in the quality of care, the challenges linked to the quality of care $^{20}$ and the conceptual dimensions of quality ${ }^{21}$ have been identified. Thus, there is a need to analyse the factors associated with quality, as also emphasised in health policies. ${ }^{22} 23$

The quality of nursing care as perceived by surgical patients has been assessed in earlier studies ${ }^{11} 192425$ while available instruments are reported in reviews. ${ }^{26}$ Generally, three patient-centred perspectives can be identified. The first highlights patients' personal experience of care. The key factor is whether the experience has been positive, assessing patients' satisfaction, ${ }^{27}{ }^{28}$ the significance of patient education for satisfaction, ${ }^{29}$ and associations between patient experience and the technical quality of care. ${ }^{5}$ The second perspective highlights patients' assessment of the success of their care as well as quality ratings. For example, in a large survey, ${ }^{17}$ hospitals were given quality ratings by patients, revealing variation between different countries: high ratings ranged from $35 \%$ in Spain to close to $60 \%$ in the USA, Switzerland, Finland and Ireland. In a Special Eurobarometer, ${ }^{30}$ the overall quality of healthcare was mainly $(71 \%)$ estimated as good by EU citizens. The third perspective highlights patients' evaluations of their empowerment and the use and control of their own resources during the care. In this study, the perceived quality of surgical nursing care is a combination of these three perspectives, based on an action-oriented approach to nursing care, consisting of the evaluation of the actor (ie, the nurse), the action or activities, the prerequisites of the action, environmental factors and the control experienced by the patients themselves. $^{2431}$

In surgical nursing, the focus has been on preoperative education $^{1632}$ and the needs or expectations for knowledge ${ }^{33}$ The flow of information during the perioperative process is identified as a central component of the continuity of care $^{34}$; higher levels of knowledge are associated with lower healthcare costs ${ }^{35}$; ; patient information is a fundamental factor for recovery at home, ${ }^{37}$ improves pain management, ${ }^{38}$ is one component in perceiving safety in surgical care, ${ }^{3}{ }^{16}$ can improve the self-care of surgical patients and their recovery at home, ${ }^{37}$ decrease anxiety ${ }^{91633}$ and fear, ${ }^{39}$ and improve quality of life. ${ }^{4041}$ Furthermore, educational activities have been included among quality factors ${ }^{42}$ even though inpatient satisfaction did not appear to be influenced by the quality of the medical information. However, there are also conflicting results. ${ }^{43} 44$

The focus of research in surgical patient education varies. Most commonly, the focus is on the sufficiency of information or knowledge for surgical patients, methods of patient education and the effect of patient education on patients' recovery. ${ }^{29}$ The provision of information is, however, inconsistent ${ }^{29}$ and unmet patient information needs have been identified. ${ }^{24} 45-48$ In other studies, patients required more anaesthetic information, ${ }^{37}$ and a patient-centred emphatic approach produced satisfaction with the information received. ${ }^{49}$ As for the content of education, surgical patients seem to receive mainly bio-physiological knowledge, such as knowledge about the disease, symptoms and the physiological elements of care. $^{1233}$

There is limited evidence about the connection between the perceived quality of surgical nursing care and patient education, which may be due to the complex nature of the concept of nursing care quality. ${ }^{21}$ In our previous study, a connection was found between the perceived quality of internal-medical care of hospital patients and their education. ${ }^{50}$ However, the nature of nursing care in internal medical facilities is different from surgical nursing care where hospitalisation times are shorter and recovery after the surgical procedure requires patients' own activities. In this study, surgical patients' education is assessed by the perceived level of received knowledge in the perioperative process. Received knowledge is defined ${ }^{3351}$ as the knowledge that is received from professionals, understood by patients and connected with the patients' own knowledge and action base. Thus, it is more than just information given by professionals: it is the knowledge that the patients have to experience.

The focus of this study is clinical: we aim to analyse whether the perceived quality of surgical nursing is connected with patient education. The following research questions will be addressed:

1. What is the level of the perceived quality of care among hospitalised surgical patients?

2. What is the level of received knowledge among hospitalised surgical patients?

3. What is the relationship between the level of the perceived quality of care and the level of received knowledge among hospitalised surgical patients? 


\section{METHODS}

\section{Design}

This study used a cross-sectional, correlational design with surgical patients. Data were collected from hospitalised surgical patients before discharge in one university hospital district (out of five) in Finland. The hospital district is a large organisation responsible for the arrangement of specialised medical treatment and care. In university hospital districts, there is a high emphasis on acute care and research. Each university hospital has its own area of responsibility where they organise specialised treatment and care; this university district covers 869447 citizens. $^{52}$

\section{Sample and data collection}

The data were collected over a period of 12 weeks in 2013 (February-April) from hospitalised surgical patients. Patient education instructions and procedures are documented in the hospital district, and they are mainly considered to be uniform between the surgical units. The sample consisted of patients from eight different surgical units including all main areas of surgery (digestive, urology, orthopaedic, heart and thorax, gynaecological, eye and ear). The inclusion criteria for the patients were as follows: (1) over 16 years of age, (2) able to self-administer the instruments, (3) able to understand Finnish/ Swedish (Swedish is the second national language in Finland) and (4) voluntary participation. For estimation of the sample size, a power analysis was performed for the Good Nursing Care Scale (GNCS). In the power analysis, an estimated effect size of level 0.1 (weak difference) was used in the calculations and $90 \%$ test power with significance level 0.05 .

Power calculation is based on individual item (four levels) percentage distribution comparison using background variables, with effect size of level 0.1 (weak difference). With $90 \%$ power, significance level 0.05 and effect size of level 0.1 (weak difference), the minimum sample size is 245 .

The data collection was performed in collaboration with voluntary contact nurses in the units trained by the researchers. The questionnaires with information letters were distributed to all eligible patients; 480 patients completed the instruments at the end of their hospital period and returned them in a closed envelope to a letterbox in their unit. Patients were expected to respond individually, without discussing with other patients and/ or family members.

\section{Instrumentation}

The data were collected using two structured instruments: one measuring the perceived quality of nursing care experienced by patients, The Good Nursing Care Scale, GNCS, V.3 with 40 items, ${ }^{31}$ and one measuring the received knowledge of hospital patients, RKhp, original version with 40 items. ${ }^{53}$ The GNCS was originally developed for surgical patients. It is based on action theory of nursing and divided into seven quality categories: nurses' characteristics (actor, five items, eg, honest, careful and willingness to serve), nursing activities (activities, six items, eg, professional manner, informed about the treatment, encouraged and supported mentally), preconditions for care (preconditions, five items, eg, nurses' knowledge and skills are up to date, evidence-based knowledge and patients' good is a priority), nursing environment (environment, five items, eg, safety, preventing the spread of infections, identity checks and personal integrity), proceeding of the nursing process (process, six items, eg, how fluent is the nursing process, collaboration between different care organisations and informing the patient about discharging), patients' management strategies (outcomes, seven items, eg, patients' opinions are taken into account, patients are aware of the treatment and financial costs and benefits) and collaboration with family members (collaboration, six items, eg, family members are informed, heard, supported and participate in care). The GNCS has been used among surgical patients ${ }^{2454}$ and in different countries. ${ }^{556}$ The items are rated on a four-point scale from 'fully agree' (4) to 'fully disagree' (1); the option 'cannot say' $(0)$ is also given. Average scores of 1.0-1.5 indicate the very low quality of care, 1.6-2.0 low, 2.1-2.5 fairly low, 2.6-3.0 fairly high, $3.1-3.5$ high and 3.6-4.0 very high quality of care; 'high quality' was considered a sufficient level. The validity of the Good Nursing Care scale has been stated in earlier studies; this has to do with both the content $\left(\mathrm{eg},{ }^{24}{ }^{50}{ }^{57}\right)$ and construct validity $\left(\mathrm{eg},{ }^{24} 5758\right.$ ). The internal consistency reliability by using Cronbach's alpha coefficients is sufficient, ranging between 0.7 and $0.96^{50} 57$ in the subcategories and between 0.81 and $0.94^{54} 56$ for the whole scale.

The RKhp is based on the concept of patient education as an empowering nursing intervention. ${ }^{33}{ }^{53}$ It is divided into six dimensions: knowledge about bio-physiological (eight items, eg, illness and symptoms), functional (eight items, eg, mobility, nutrition and sleep), experiential (three items, eg emotions and experiences), ethical (nine items, eg, patient rights and confidentiality), social (six items, eg, significant others and patient organisations) and financial (six items, eg, costs and benefits) domains. The RKhp has been validated among surgical and internal-medical hospital patients. ${ }^{250}$ The items are rated on a four-point scale from 'fully agree' (4) to 'fully disagree' (1); the option 'cannot say' (0) is also provided. Higher scores reflect more knowledge received; expecting 3 (agree) being the sufficient level. The validity of the RKhp has been confirmed in earlier studies; this has to do with both the content $\left(\mathrm{eg}^{24} 5057\right.$ ) and construct validity $\left(\mathrm{eg},{ }^{24} 5758\right.$ ). The internal consistency reliability by using Cronbach's alpha coefficients is sufficient, ranging between 0.89 and 0.95 for the six dimensions and between $0.93^{2}$ and $0.80^{33}$ for the total scale.

The background factors connected with the two instruments included patients' sociodemographic (age, gender, level of education, work status and living arrangement) and hospitalisation-related (type of admission, reason for 
a hospital stay, earlier visit in the hospital and length of hospital stay) factors and patients' health status.

\section{Ethical issues}

The study was conducted in accordance with ethical principles. ${ }^{59}$ Ethical approval was obtained from the Ethical Committee of the University of Turku (Code 2/2013) and permission for the study was granted according to the procedures of the hospital district. Using written information letters, patients were informed about the purpose of the study and the principles of voluntary and anonymous participation. Returning the questionnaires was regarded as voluntary consent by the patients and no separate informed consent was required. No personal identification information was collected and the researchers did not have access to the patients' personal hospital files. Data were handled confidentially in the university database, allowing access only to researchers, and stored in an electronic data matrix for potential secondary analyses.

\section{Data analysis}

Data were analysed statistically using the SPSS V.21.0. Descriptive statistics (frequencies, percentages, means and SD) were used to describe the sample and study variables. Altogether seven sum variables in the GNCS were formulated based on the theoretical dimensions of the scale, with 'high quality' (mean 3.1-3.5) considered as sufficient. Pearson's correlation coefficients were used to analyse the association between the scales. Multifactor analysis of variance was computed to analyse the amount of variance in the perceived quality of surgical nursing care (GNCS) explained by background factors and the knowledge received (RKhp). The background factors used in the model were sociodemographic, hospitalisation-related and patients' health status and general questions about knowledge received (yes/no), having knowledge about the progress of treatment and care (yes/ no). A p value of $\leq 0.05$ was considered statistically significant. Cronbach's alpha coefficient was used to analyse the internal consistency of both instruments.

\section{Patient and public involvement}

The informants in this study were surgical patients and the main research interest was in their perspectives on the knowledge and quality of care. The instrument used, the GOOD NURSING CARE-SCALE, was originally developed in collaboration with patients and includes content that is relevant to them. Patients were not involved in the recruitment of respondents. Patients' views of the instruments as well as their understandability were reviewed in connection with the piloting of the instruments. The implementation of the results is important for patients because the aim is to improve the quality of care. The professionals in each collaborating unit will be informed of the results to enable discussion and consideration of the meaning of the results in the units in question. Furthermore, open lectures will be arranged as part of continuing education for professionals, and the main patient association will also be informed of the results through their own journal. In the data collection, no patient advisers were used.

\section{RESULTS}

\section{Demographics of surgical patients}

The sample size of the patients was $480(=n)$, their average age was 59 (SD 17) years and a slight majority were men $(58 \%, \mathrm{n}=277)$. Their educational level was mainly vocational qualification $(49 \%)$ or a comprehensive school $(35 \%)$. More than half of the patients were retirees $(53 \%)$ and most of them co-habited with other family members $(75 \%)$. A majority had elective admission $(67 \%)$ and previous experiences of hospitalisation $(87 \%)$, even in the same hospital $(60 \%)$. The average length of hospital stay was 4.4 (SD 4.2) days. Most patients had a surgical procedure or operation during their stay $(78 \%)$. At the moment of responding to the instruments, most patients evaluated their own health status as good (42\%) or fairly $\operatorname{good}(47 \%)$ (table 1$)$.

\section{Surgical patients' perceptions of the quality of nursing care}

In general, the patients perceived the quality of surgical nursing as high (GNCS, mean 3.47, table 2). The highest level of quality was perceived in environmental (mean 3.84 ) and staff characteristics (mean 3.82), while the lowest was reported in collaboration with family members (mean 3.00) and in support of patients' own management strategies (mean 3.55).

\section{Surgical patients' perceptions of received knowledge}

In general, most of the patients estimated the received knowledge to be sufficient ( $\mathrm{n}=324,80 \%$ of those who responded to the question) and they were familiar with the proceeding of their care and treatment after discharge $(390,85 \%)$. On the other hand, a considerable proportion $(n=71,15 \%)$ of the respondents were not familiar with their care and treatment process even though the data were collected just prior to discharge from the hospital.

On the received knowledge of hospital patients scale, the mean of total scale (RKhp, mean 3.33, table 2) indicated a high level of received knowledge, being highest in the bio-physiological domain (mean 3.47) and the lowest in the area of financial knowledge (mean 2.58) where the number of respondents was also clearly lower than in the bio-physiological domain.

\section{Relationship between the quality of surgical nursing care and received knowledge}

There was a strong correlation between the perceived quality of surgical nursing care (GNCS) and received knowledge (RKhp) $(\mathrm{r}=0.666, \mathrm{p}<0.001)$ : the higher the perceived level of received knowledge, the higher the assessments of the quality of surgical nursing care.

Univariate analysis of variance was computed for the sociodemographic, hospitalisation-related, health 


\begin{tabular}{|c|c|c|c|c|c|c|}
\hline Variable & $\mathbf{n}$ & $\%$ & Mean & SD & Min & Max \\
\hline Age & 473 & & 59.3 & 17.0 & 16 & 93 \\
\hline \multicolumn{7}{|l|}{ Gender } \\
\hline Male & 277 & 58 & & & & \\
\hline Female & 200 & 42 & & & & \\
\hline \multicolumn{7}{|l|}{ Education } \\
\hline $\begin{array}{l}\text { Comprehensive } \\
\text { school }\end{array}$ & 169 & 36 & & & & \\
\hline $\begin{array}{l}\text { Matriculation } \\
\text { examination }\end{array}$ & 19 & 4 & & & & \\
\hline $\begin{array}{l}\text { Vocational } \\
\text { qualification }\end{array}$ & 237 & 50 & & & & \\
\hline University degree & 48 & 10 & & & & \\
\hline \multicolumn{7}{|l|}{ Work status } \\
\hline Employed & 173 & 36 & & & & \\
\hline Unemployed & 24 & 5 & & & & \\
\hline Retired & 255 & 53 & & & & \\
\hline $\begin{array}{l}\text { Stay-at-home mom/ } \\
\text { dad }\end{array}$ & 7 & 1 & & & & \\
\hline Student & 18 & 4 & & & & \\
\hline \multicolumn{7}{|l|}{ Living arrangement } \\
\hline Live alone & 115 & 24 & & & & \\
\hline $\begin{array}{l}\text { Live with family } \\
\text { member(s) }\end{array}$ & 359 & 76 & & & & \\
\hline \multicolumn{7}{|c|}{ Type of admission into hospital/unit } \\
\hline $\begin{array}{l}\text { Admitted as an } \\
\text { emergency patient }\end{array}$ & 135 & 29 & & & & \\
\hline $\begin{array}{l}\text { Admitted as an } \\
\text { elective patient }\end{array}$ & 323 & 71 & & & & \\
\hline
\end{tabular}

First time at hospital generally

$\begin{array}{lrr}\text { Yes } & 50 & 11 \\ \text { No } & 420 & 89\end{array}$

First time in this hospital

\begin{tabular}{lllllll} 
Yes & 177 & 38 & & & & \\
\multicolumn{1}{|l}{ No } & 286 & 62 & & & & \\
$\begin{array}{l}\text { Days spent in this } \\
\text { hospital/unit }\end{array}$ & 448 & & 4.4 & 4.2 & 1 & 42 \\
$\begin{array}{l}\text { Reason for hospitalisation } \\
\text { Reason for hos }\end{array}$ & & & & & \\
\hline
\end{tabular}

Reason for hospitalisation

$\begin{array}{lrr}\begin{array}{l}\text { An examination } \\ \begin{array}{l}\text { Surgical treatment, } \\ \text { procedures }\end{array}\end{array} & 373 & 39 \\ \begin{array}{l}\text { Medication and/or } \\ \text { infusion therapy }\end{array} & 60 & 6 \\ \begin{array}{l}\text { Guidance/ } \\ \text { counselling visit due } \\ \text { to the illness }\end{array} & 481 & 51 \\ \begin{array}{l}\text { Other } \\ \text { Any chronic disease }\end{array} & 6 & 1 \\ \text { No } & 234 & 51\end{array}$

Continued
Table 1 Continued

\begin{tabular}{|c|c|c|c|c|c|c|}
\hline Variable & $\mathbf{n}$ & $\%$ & Mean & SD & Min & Max \\
\hline Yes & 228 & 49 & & & & \\
\hline
\end{tabular}

Current state of health in comparison with normal state of health

\begin{tabular}{lrr} 
Excellent & 34 & 7 \\
Good & 196 & 42 \\
Fairly good & 216 & 47 \\
Poor & 17 & 4 \\
\hline
\end{tabular}

status and knowledge-related factors in association with the perceived quality of surgical nursing care (GNCs) (table 3). The model was statistically significant $(\mathrm{F}=16.7$, df 22, $\mathrm{p}<0.001)$, explaining $55 \%$ of the variance in the quality of surgical nursing care $\left(\mathrm{R}^{2}=0.554\right)$. Statistically significant predictors were the level of received knowledge in general (RKhp total, $\mathrm{F}=19.5$, df $1, \mathrm{p}<0.001$ ), whether the respondent had received sufficient knowledge before hospitalisation ( $\mathrm{F}=7.6$, df 1 ), $\mathrm{p}=0.006)$, having knowledge about how care and treatment proceed after hospitalisation $\mathrm{F}=14.6$, df $1, \mathrm{p}<0.001$ ), and perceived health status $(\mathrm{F}=3.06$, df $3, \mathrm{p}=0.028)$.

\section{DISCUSSION}

In this study, we analysed the possible relationship between the perceived quality of surgical nursing care and the knowledge received by surgical hospital patients. The study was based on the assumption that a higher level of received knowledge would also improve the perceived quality of surgical nursing care. There is no systematic research evidence for this connection even though patient education is a natural part of nursing care and we have already identified this connection among internal medical patients. ${ }^{50}$ Thus, by demonstrating the connection in different clinical fields, in this case, among surgical patients, strategic planning of patient education can be incorporated into many existing quality assurance programmes. The results strengthened our assumption and indicated the existence of a connection between patient education and the quality of care. The finding is clinically important due to the many changes that have taken place in the surgical field in recent years, such as shorter hospitalisation times ${ }^{15}$ and reduction in the time nurses have for patient education. Our results provide evidence that by improving the quality of patient education, we can also improve the quality of care. However, the improvement would require new technological, educational solutions, support for patients' self-management and postoperative recovery at home, as well as analysis of patients' knowledge expectations preoperatively. ${ }^{232}$ Traditionally, self-management and patient empowerment have been discussed more with reference to medical patients with chronic conditions (such as patients with diabetes, 


\begin{tabular}{lllll}
\hline \multicolumn{2}{l}{ Table 2 Descriptive statistics of the scales } & & & \\
\hline Scale & Items & $\mathbf{n}$ & Mean (SD) & Cronbach's $\boldsymbol{\alpha}$ \\
\hline GNCS & 40 & 476 & $3.47(0.34)$ & 0.940 \\
Nursing staff characteristics & 5 & 470 & $3.82(0.35)$ & 0.773 \\
Nursing activities & 6 & 467 & $3.70(0.43)$ & 0.839 \\
Preconditions for care & 5 & 453 & $3.72(0.44)$ & 0.797 \\
Nursing environment & 5 & 466 & $3.84(0.30)$ & 0.660 \\
Proceeding of the nursing process & 6 & 459 & $3.70(0.40)$ & 0.709 \\
Patients' management strategies & 7 & 447 & $3.55(0.50)$ & 0.842 \\
Collaboration with family members & 6 & 316 & $3.00(0.93)$ & 0.940 \\
RKhp & 40 & 438 & $3.33(0.74)$ & 0.987 \\
Bio-physiological & 8 & 431 & $3.47(0.63)$ & 0.913 \\
Functional & 8 & 408 & $3.40(0.72)$ & 0.949 \\
Experiential & 3 & 335 & $3.09(0.96)$ & 0.914 \\
Ethical & 9 & 374 & $3.11(0.86)$ & 0.958 \\
Social & 6 & 327 & $2.83(1.05)$ & 0.949 \\
Financial & 6 & 259 & $2.58(1.11)$ & 0.975
\end{tabular}

Observed range 1-4 $(n=480)$.

GNCS, Good Nursing Care Scale; RKhp, received knowledge of hospital patient.

asthma or rheumatoid arthritis), but short hospital stays make it relevant for surgical patients as well.

\section{Surgical patients' perceptions of the quality of nursing care}

The perceived quality of surgical nursing care seems to be high. The highest level of quality was seen in the environment and characteristics of the staff, confirming earlier findings. ${ }^{54-57}$ Quality improvement is still needed in collaboration with family members, as also indicated by previous studies, ${ }^{60}$ and in support of patients' own management strategies. ${ }^{2}$ It may be that collaboration with family members was not identified as being so important among this sample of adult patients even though they have to have a significant other to accompany them home from the hospital and stay over the first night. In the future, however, the increase in the number of older patients will mean special emphasis on family collaboration. ${ }^{8}$ In the internal medical field, typically involving older patients, we have already identified the connection between the quality of care and patient education. ${ }^{50}$

\section{Surgical patients' perceptions of received knowledge}

The knowledge received by patients was mainly sufficient. In this study, received knowledge is not only the information given, but also the patients' experience of having it. The sufficiency of knowledge was true particularly in the bio-physiological field, but less so in the financial field. In the future, the number of surgical patients with multidimensional health problems will increase, creating a need for empowering multidimensional knowledge. ${ }^{61}$ This also includes financial knowledge, the area where the least amount of knowledge was received in this sample. This result is in line with earlier studies. For example, the highest difference between received and expected knowledge was seen in the financial dimension, ${ }^{2}$ and patients' knowledge expectations on financial issues are not fully met. ${ }^{62}$ In the future, patients in many countries will have to understand the financial components of their care, and in order to empower patients, nurses have to provide them with a relevant amount of financial knowledge, or at least make sure that patients are aware of where they can find information. Knowledge about financial issues may have a positive impact on both patients' decision-making and the healthcare system. ${ }^{62}$

Traditionally, the emphasis on surgical care has been on preoperative education. ${ }^{63}$ However, our results indicate a need to establish a continuous educational programme for improving the quality of surgical nursing care. This could be designed as a mobile application; for example, allowing patients to follow it throughout the perioperative process. ${ }^{14}$ It is clear that patients' perceived health status is also of significance in the educational process, as was also the case in our data.

The limitations of this study have to do with the sample and data collection. The sample, consisting of different types of surgical patients, was collected in one university hospital district (out of five). Surgical procedures share sufficient similarities to combine the patients into the same dataset; the educational procedures and written educational materials are largely similar. This assumption can be criticised. Our aim, however, was not to compare patient education in different clinical fields but to analyse the connection between education and perceived quality of care. In many countries, there is increasingly a mix of surgical patients in the same wards, 
Table 3 Multifactor analysis of variance of patients' ( $n=480)$ sociodemographic, hospitalisation-related, health status and knowledge-related variables on perceived quality of surgical nursing care

\begin{tabular}{|c|c|c|}
\hline Variable & $F(d f)^{*}$ & $P$ value \\
\hline Model & $16.68(22)$ & $<0.001$ \\
\hline Intercept & $438.69(1)$ & $<0.001$ \\
\hline \multicolumn{3}{|l|}{ Sociodemographic variables } \\
\hline Age & $0.34(1)$ & 0.563 \\
\hline Gender & $0.00(1)$ & 0.992 \\
\hline Education & $0.75(3)$ & 0.526 \\
\hline Work status & $0.84(4)$ & 0.500 \\
\hline Living arrangement & $0.40(1)$ & 0.528 \\
\hline \multicolumn{3}{|l|}{ Hospitalisation-related variables } \\
\hline Type of admission & $0.01(2)$ & 0.989 \\
\hline First time in hospital & $0.02(1)$ & 0.895 \\
\hline First time in this hospital & $0.70(1)$ & 0.403 \\
\hline The length of hospital stay & $0.30(1)$ & 0.583 \\
\hline \multicolumn{3}{|l|}{ Health status-related variables } \\
\hline Any chronic disease(s) & $1.15(1)$ & 0.285 \\
\hline $\begin{array}{l}\text { Perceived health status in } \\
\text { general }\end{array}$ & $3.06(3)$ & 0.028 \\
\hline \multicolumn{3}{|l|}{ Knowledge-related variables } \\
\hline $\begin{array}{l}\text { Sufficient knowledge about } \\
\text { care and treatment }\end{array}$ & $7.59(1)$ & 0.006 \\
\hline $\begin{array}{l}\text { Knowledge about proceeding of } \\
\text { care and treatment }\end{array}$ & $14.56(1)$ & $<0.001$ \\
\hline RKhp total score & $159.51(1)$ & $<0.001$ \\
\hline
\end{tabular}

$\mathrm{R}$-square $=0.554$; adjusted $\mathrm{R}$-square $=0.521$.

${ }^{*} F$-value, df df with $p$ value.

which poses a challenge for nurses to recognise the similarities and individual needs in the patients' educational expectations. The sample corresponds rather well with the average age of patients and the average length of hospital stay in Finland, ${ }^{64} 4.0$ days in the department of digestive surgery and 3.0 days in the department of urology, and the patients' health status was rather good at the time of responding. New samples are needed to analyse the connection between the quality of care and patient education in more specific patient groups, as well as to improve international comparisons. International comparisons in the field of orthopaedic patient education already show a lot of similarities, but also differences in patients' expectations and received knowledge ${ }^{2}$ and in educational practices. ${ }^{65}$ Analysis of health literacy and/ or individual learning strategies of patients should also be included in further analyses to deepen our understanding of the cognitive processes of patients.

Furthermore, there were some limitations to the process. For example, we were not able to control the completion of the instruments. The aim was for the patients to respond individually at the end of their hospital stay, but it is possible that they may have collaborated with other patients and/or significant others. The missing response rate and problems in handling missing data are also a limitation. We planned to control the missing data (eg, patients' refusals), but in real life, we did not succeed in this due to the hectic clinical practice and high flow of patients. However, the sample size was based on power analysis and was sufficiently large.

In the data collection, we used two previously validated instruments $\left(\mathrm{eg}^{2}{ }^{26}\right)$. In this sample, the internal consistency of the instruments was acceptable for both the GNCS (Cronbach's 0.66-0.94) and the RKhp (Cronbach's alpha $0.91-0.98$ ) subscales, similarly as in previous studies. The content of the instrument consists of the main areas of nursing care and content validity has been estimated by professionals in different countries. ${ }^{2}{ }^{57}$ All the patients meeting inclusion criteria had a possibility to complete the instruments. Both of the instruments are self-reports by patients, which is a fundamental criterion for patient-centred care and treatment. ${ }^{11}{ }^{12}$ In the future, there is a need to combine patients' perceptions with healthcare organisations' register data as well as with patient-peers' and healthcare professionals' observations. It would also be relevant to include organisational elements in the analyses of patient education. These would include elements such as organisational policies, educational guidelines and quality assurance programmes. It would be particularly important to analyse the significance of policies on adequate staffing of nurses for patient education.

\section{CONCLUSIONS}

Based on the results of this study, the relationship between the quality of surgical nursing care and received knowledge as perceived by surgical hospital patients was confirmed. This finding supports a study conducted among medical patients. ${ }^{50}$ In the future, there is a need for more detailed research including, for example, specific knowledge about educational activities implemented by nurses and the learning strategies used by patients. The results also provide evidence to establish intervention studies for improving the connection. Furthermore, the educational competence of nurses and graduating nursing students warrants future analysis of health literacy levels.

Clinical resources: The Empowering Patient Education research program in patient education http://www.utu. $\mathrm{fi} / \mathrm{en} /$ units/med/units/hoitotiede/research/projects/ epe/Pages/home.aspx.

Contributors The conception and design of the study and acquisition of data: WG and HL-K. Analysis and interpretation of data: WG, JK, RS and HL-K. Drafting the article or revising it: WG, HM, JK, RS and HL-K. Final approval of the version to be submitted has been made by all authors.

Funding This work was supported by State Government Funding of the Health District of Southwest Finland for data collection (grant number 13762, 2013). The funding source had no involvement in the collection, analysis and interpretation of data.

Competing interests None declared.

Patient consent for publication Not required. 
Provenance and peer review Not commissioned; externally peer reviewed.

Data sharing statement № in future additional unpublished data from this study is available to anybody.

Open access This is an open access article distributed in accordance with the Creative Commons Attribution Non Commercial (CC BY-NC 4.0) license, which permits others to distribute, remix, adapt, build upon this work non-commercially, and license their derivative works on different terms, provided the original work is properly cited, appropriate credit is given, any changes made indicated, and the use is non-commercial. See: http://creativecommons.org/licenses/by-nc/4.0/.

\section{REFERENCES}

1. Rankinen S, Salanterä S, Heikkinen K, et al. Expectations and received knowledge by surgical patients. Int J Qual Health Care 2007;19:113-9.

2. Klemetti S, Leino-Kilpi H, Cabrera E, et al. Difference between received and expected knowledge of patients undergoing knee or hip replacement in seven European countries. Clin Nurs Res 2015;24:624-43.

3. Mako T, Svanäng P, Bjerså K. Patients' perceptions of the meaning of good care in surgical care: a grounded theory study. BMC Nurs 2016;15:47.

4. Wong EL, Coulter A, Hewitson P, et al. Patient experience and satisfaction with inpatient service: development of short form survey instrument measuring the core aspect of inpatient experience. PLOS One 2015;10.e0122299.

5. Doyle C, Lennox L, Bell D. A systematic review of evidence on the links between patient experience and clinical safety and effectiveness. BMJ Open 2013;3:e001570.

6. Ronco M, lona L, Fabbro C, et al. Patient education outcomes in surgery: a systematic review from 2004 to 2010. Int J Evid Based Healthc 2012;10:309-23.

7. Schmidt M, Eckardt R, Scholtz K, et al. Patient Empowerment Improved Perioperative Quality of Care in Cancer Patients Aged $\geq 65$ Years - A Randomized Controlled Trial. PLoS One 2015;10:e0137824.

8. Schoberer D, Leino-Kilpi H, Breimaier HE, et al. Educational interventions to empower nursing home residents: a systematic literature review. Clin Interv Aging 2016;11:1351-63.

9. Wilson C, Mitchelson A, Tzeng T, et al. Caring for the surgically anxious patient: a review of the interventions and a guide to optimizing surgical outcomes. American Journal of Surgery 2015;jun 2. pii: S0002-9610(15)00291-3. doi:10.1016/j.amjsurg.2015.03.023 (Epub ahead of print).

10. Kliot T, Zygourakis CC, Imershein S, et al. The impact of a patient education bundle on neurosurgery patient satisfaction. Surg Neurol Int 2015(6(Suppl 22):567-72.

11. Edvardsson D, Watt E, Pearce F. Patient experiences of caring and person-centredness are associated with perceived nursing care quality. J Adv Nurs 2017;73.

12. Castro EM, Van Regenmortel T, Vanhaecht K, et al. Patient empowerment, patient participation and patient-centeredness in hospital care: A concept analysis based on a literature review. Patient Educ Couns 2016;99:1923-39.

13. Ellner SJ, Joyner PW. Information technologies and patient safety. Surg Clin North Am 2012;92:79-87.

14. Briggs M, Wilkinson $C$, Golash A. Digital multimedia books produced using iBooks Author for pre-operative surgical patient information. J Vis Commun Med 2014;37(3-4):59-64.

15. Eurostat. Health. Eurostat regional yearbook, 2014. http://ec.europa. eu/eurostat/web/products-statistical-books/-/KS-HA-14-001-02. (Accessed January 3rd 2016).

16. Sjöstedt L, Hellström R, Stomberg MW. Patients' need for information prior to colonic surgery. Gastroenterol Nurs 2011;34:390-7.

17. Aiken LH, Sermeus W, Van den Heede K, et al. Patient safety, satisfaction, and quality of hospital care: cross sectional surveys of nurses and patients in 12 countries in Europe and the United States. BMJ 2012;344:e1717-14

18. Lee CK, Lee IF. Preoperative patient teaching: the practice and perceptions among surgical ward nurses. J Clin Nurs 2013;22(1718):2551-61.

19. Koy V, Yunibhand J, Angsuroch Y, et al. Relationship between nursing care quality, nurse staffing, nurse job satisfaction, nurse practice environment, and burnout: literature review. International Journal of Research in Medical Sciences 2015b;3:1825-31.

20. Jangland E, Nyberg B, Yngman-Uhlin P. 'It's a matter of patient safety': understanding challenges in everyday clinical practice for achieving good care on the surgical ward - a qualitative study. Scand J Caring Sci 2017;31:323-31.

21. Koy V, Yunibhand J, Angsuroch Y. Nursing care quality: a concept analysis. International Journal of Research in Medical Sciences 2015a;3:1832-8.

22. EU. Third health programme (2014-2020). 2014 http://ec.europa.eu/ health/programme/policy_en (Accessed 5 Dec 2016).

23. WHO. Health 2020: the European policy for health and well-being. 2016 http://www.euro.who.int/en/health-topics/health-policy/health2020-the-european-policy-for-health-and-well-being/about-health2020/priority-areas (Accessed 5 Dec 2016).

24. Leinonen $T$, Leino-Kilpi $H$, Ståhlberg MR, et al. The quality of perioperative care: development of a tool for the perceptions of patients. J Adv Nurs 2001;35:294-306.

25. Copnell B, Hagger V, Wilson SG, et al. Measuring the quality of hospital care: an inventory of indicators. Intern Med J 2009;39:352-60.

26. Koy V, Yunibhand J, Angsuroch Y. The quantitative measurement of nursing care quality: a systematic review of available instruments. Int Nurs Rev 2016;63:490-8.

27. Kutney-Lee A, McHugh MD, Sloane DM, et al. Nursing: a key to patient satisfaction. Health Aff 2009;28:w669-77.

28. Peden CJ, Grocott MP. National Research Strategies: what outcomes are important in peri-operative elderly care? Anaesthesia 2014;69(Suppl 1):61-9.

29. Suhonen R, Leino-Kilpi H. Adult surgical patients and the information provided to them by nurses: a literature review. Patient Educ Couns 2006;61:5-15.

30. Special Eurobarometer 411. Patient safety and quality of care report. 2014.

31. Leino-Kilpi H, Vuorenheimo J. The patient's perspective on nursing quality: developing a framework for evaluation. Int $J$ Qual Health Care 1994;6:85-95.

32. Pellinen T, Villberg J, Raappana M, et al. Knowledge expectations of recently diagnosed patients with knee osteoarthritis. J Adv Nurs 2016;72:2857-68.

33. Ryhänen AM, Rankinen S, Siekkinen M, et al. The impact of an empowering Internet-based Breast Cancer Patient Pathway program on breast cancer patients' clinical outcomes: a randomised controlled trial. J Clin Nurs 2013;22(7-8):1016-25.

34. Renholm M. Continuity of patient care in day surgery. Anneles Universitatis Turkuensis D 1199. Department of Nursing Sciences, Turku: University of Turku 2015.

35. Colombara F, Martinato M, Girardin G, et al. Higher levels of knowledge reduce health care costs in patients with inflammatory bowel disease. Inflamm Bowel Dis 2015;21:615-22.

36. Lo SF, Wang YT, Wu LY, et al. A cost-effectiveness analysis of a multimedia learning education program for stoma patients. J Clin Nurs 2010;19(13-14):1844-54.

37. Mitchell $\mathrm{M}$. Home recovery following day surgery: a patient perspective. J Clin Nurs 2015;24(3-4):415-27.

38. Jacobsson LR, Friedrichsen M, Göransson A, et al. Impact of an active patient education program on gastrointestinal symptoms in women with celiac disease following a gluten-free diet: a randomized controlled trial. Gastroenterol Nurs 2012;35:200-6.

39. Shahmansouri N, Janghorbani M, Salehi Omran A, et al. Effects of a psychoeducation intervention on fear and anxiety about surgery: randomized trial in patients undergoing coronary artery bypass grafting. Psychol Health Med 2014;19:375-83.

40. Pool MK, Nadrian H, Pasha N. Effects of a self-care education program on quality of life after surgery in patients with esophageal cancer. Gastroenterol Nurs 2012;35:332-40.

41. Yu WZ, Ouyang YQ, Zhang Q, et al. The effectiveness of a structured educational intervention on disease-related misconception and quality of life in patients with irritable bowel syndrome. Gastroenterol Nurs 2014;37:289-98.

42. Fröjd C, Swenne CL, Rubertsson C, et al. Patient information and participation still in need of improvement: evaluation of patients' perceptions of quality of care. J Nurs Manag 2011;19:226-36.

43. McDonald S, Hetrick S, Green S. Pre-operative education for hip or knee replacement. Cochrane Database of Systematic Reviewers $2004 ; 1$.

44. Barlow C, Cooke D, Mulligan K, et al. A critical review of selfmanagement and educational interventions in inflammatory bowel disease. Gastroenterol Nurs 2010;33:11-18.

45. O'Connor G, Coates V, O'Neill S. Exploring the information needs of patients with cancer of the rectum. Eur J Oncol Nurs 2010;14:271-7.

46. Palese A, Tomietto M, Suhonen R, et al. Surgical patient satisfaction as an outcome of nurses' caring behaviors: a descriptive and correlational study in six European countries. J Nurs Scholarsh 2011;43:341-50. 
47. Ringström G, Agerforz P, Lindh A, et al. What do patients with irritable bowel syndrome know about their disorder and how do they use their knowledge? Gastroenterol Nurs 2009;32:284-92.

48. Werth SL, Schutte DL, Stommel M. Bridging the gap: perceived educational needs in the inpatient to home care setting for the person with a new ostomy. J Wound Ostomy Continence Nurs 2014;41:566-72.

49. Pereira L, Figueiredo-Braga M, Carvalho IP. Preoperative anxiety in ambulatory surgery: The impact of an empathic patient-centered approach on psychological and clinical outcomes. Patient Educ Couns 2016;99:733-8.

50. Leino-Kilpi H, Gröndahl W, Pekonen A, et al. Knowledge received by hospital patients--a factor connected with the patient-centred quality of nursing care. Int J Nurs Pract 2015.21.

51. Heikkinen K, Leino-Kilpi H, Hiltunen A, et al. Ambulatory orthopaedic surgery patients' knowledge expectations and perceptions of received knowledge. J Adv Nurs 2007;60:270-8.

52. Kunnat.net. Sairaanhoitopiirien ja erityisvastuualueiden (erva) asukasluvut. 2014 http://www.kunnat.net/fi/kunnat/ sairaanhoitopiirit/asukasluvut/Sivut/default.aspx (Accessed 8 Jan 2016).

53. Leino-Kilpi H, Maenpaa I, Katajisto J. Nursing study of the significance of rheumatoid arthritis as perceived by patients using the concept of empowerment. Journal of Orthopaedic Nursing 1999;3:138-45.

54. Donmez YC, Ozbayır T. Validity and reliability of the 'good perioperative nursing care scale' for Turkish patients and nurses. $J$ Clin Nurs 2011;20(1-2):166-74

55. Rehnström L, Christensson L, Leino-Kilpi H, et al. Adaptation and psychometric evaluation of the Swedish version of the Good Nursing Care Scale for Patients. Scand J Caring Sci 2003;17:308-14.
56. Zhao SH, Akkadechanunt T, Xue XL. Quality nursing care as perceived by nurses and patients in a Chinese hospital. $J$ Clin Nurs 2009;18:1722-8.

57. Istomina N. Quality of abdominal surgical nursing care. Academic dissertation. Annales Universitatis Turkuensis D987. Department of Nursing Sciences, Turku: University of Turku, 2011.

58. Pelander T, Leino-Kilpi $\mathrm{H}$, Katajisto J. The quality of paediatric nursing care: developing the Child Care Quality at Hospital instrument for children. J Adv Nurs 2009;65:443-53.

59. WMA Declaration of Helsinki-Ethical Principles for Medical Research Involving Human Subjects. Current 2013. version http:// www.wma.net/en/30publications/10policies/b3/index.html (Accessed 3 Jan 2016)

60. Persson E, Gustavsson B, Hellström AL, et al. Information to the relatives of people with ostomies: is it satisfactory and adequate? $\mathrm{J}$ Wound Ostomy Continence Nurs 2005;32:238-45.

61. Johansson K, Leino-Kilpi H, Salanterä S, et al. Need for change in patient education: a Finnish survey from the patient's perspective. Patient Educ Couns 2003;51:239-45.

62. Copanitsanou P, Valkeapää K, Cabrera E, et al. Total Joint Arthroplasty Patients' Education on Financial Issues and Its Connection to Reported Out-of-Pocket Costs-A European Study. Nurs Forum 2017;52:97-106.

63. Turunen $\mathrm{E}$, Miettinen M, Setälä $\mathrm{L}$, et al. An integrative review of a preoperative nursing care structure. J Clin Nurs 2017;26:915-930

64. THL. Official Statistics of Finland. Episodes of care - procedures and interventions 2010. Helsinki: Terveyden ja hyvinvoinnin laitos (THL) National Institute for Health and Welfare, 2010.

65. Charalambous A, Papastavrou E, Valkeapää K, et al. Content of Orthopedic Patient Education Provided by Nurses in Seven European Countries. Clin Nurs Res 2018;27:1054773817713178. 